\title{
A Case Presentation With Tranverse Testicular Ectopia
}

\author{
Hasan Cece, ${ }^{\mathrm{a}, \mathrm{c}}$, Mahmut Abuhandan ${ }^{\mathrm{b}}$, Sema Yildiz ${ }^{\mathrm{a}}$, Omer Karakas ${ }^{\mathrm{a}}$, Ekrem Karakas ${ }^{\mathrm{a}}$
}

\begin{abstract}
Ectopic testis is defined as the aberrant location of testis in places other than the scrotum during descent from the inguinal canal after the external ring. These aberrant locations include suprapubic site, medial of the thigh, perineum, anterior abdominal wall and contralateral scrotum. An interesting and rare form of ectopic testis is transverse testicular ectopia (TTE) or in other words, cross testicular ectopia. This abnormality presents with both testicles in the same hemiscrotum. In this manuscript, we present a four-year old male case who presented to our out patients clinic with left undescended testis and was diagnosed with transverse testicular ectopia.
\end{abstract}

Keywords: Testis; Crossed ectopia; Ultrasonography

\section{Introduction}

TTE is a rare anomaly in which both testicles descend through a single inguinal canal. Ectopic location of testicles occurs in two anatomic variations. In the first group, testis

Manuscript accepted for publication January 19, 2012

${ }^{a}$ Harran University School of Medicine, Department of Radiology, Sanliurfa, Turkey

${ }^{b}$ Harran University School of Medicine, Department of Pediatrics, Sanliurfa, Turkey

${ }^{\mathrm{c}}$ Corresponding author: Hasan Cece, Harran University, Faculty of Medicine, Department of Radiology, Sanliurfa, Turkey.

Email: hasan_cece@yahoo.com

doi:10.4021/ijcp2w is stopped at some point during a normal descend which is called cryptorchidism. Cryptorchic testis might be abdominal, inguinal or prepubic. The second group refers to descend in an aberrant way. Descend of testis normally through the inguinal canal and migration to an aberrant site after passing the external ring is termed ectopic testis. Ectopic testis might be located in the superficial inguinal pouch, prepubic junction, perineum, medial of the thigh, femoral region, pubic region, dorsal of the penis or contralateral scrotum [1]. TTE is a rare form of ectopic testis. This pathology is also called contralateral ectopia where both testicles are found in a single inguinal canal [2]. In this manuscript, we present a four-year old male case that presented to our clinic with undescended testis and was diagnosed with TTE according to ultrasonography (USG) and magnetic resonance imaging (MRI).

\section{Case Report}

A 4-year-old boy presented with a left impalpable undescended testis. Family history was insignificant and examination of other systems proved normal. External genitalia were of male type and circumcision had not been performed. Left hemiscrotum was empty with normal appearing urethral meatus. Right testis was palpated in the scrotum. Diagnostic scrotal USG and pelvic MRI demonstrated empty left scrotum and double testicles in right scrotum (Fig. 1). Doppler ultrasonography demonstrated that vascular and ductal structures of the two testicles were separated. Patient was diagnosed with TTE and referred to the urology clinic.

\section{Discussion}

Testicular descent is completed during birth and testicles are found in the scrotum at birth. Delayed testicular descent is seen in $3-4 \%$ of term newborns. This rate is about $30 \%$ in premature infants [3]. There might be several causes of an empty scrotum including retractile testis, ectopic testis, anorchism, undescended testis and testicular atrophy secondary testicular torsion [3]. Descend of testis normally through the 


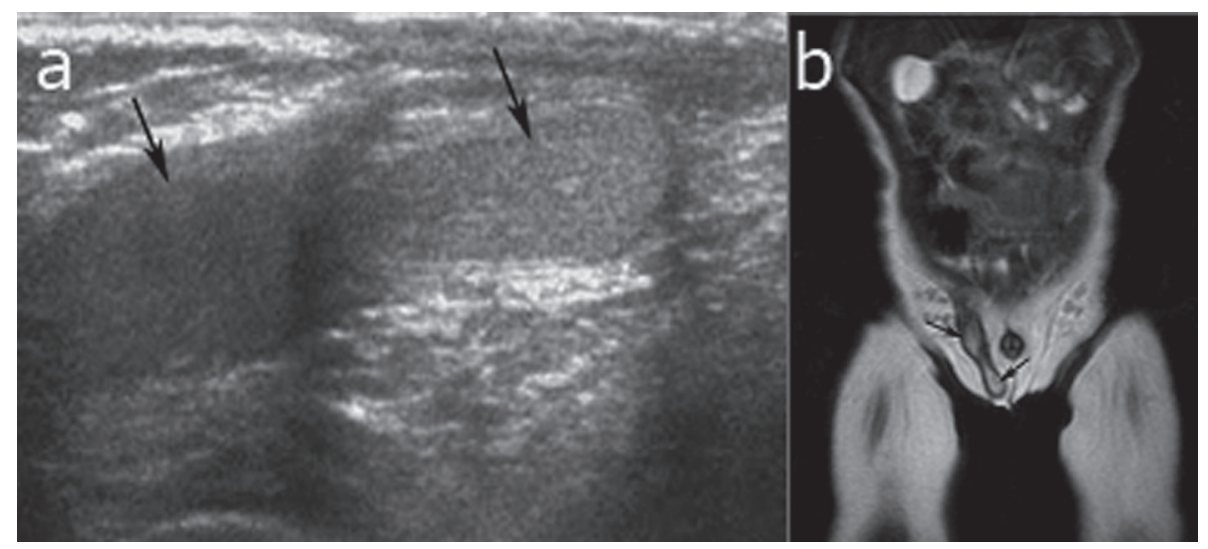

Figure 1. Ultrasonography (a) and coronal T2-weighted MR image (b) shows two testis located in the right hemiscrotum.

inguinal canal and migration to an aberrant site after passing the external ring is termed ectopic testis. Ectopic testis might be located in the superficial inguinal pouch, penopubic junction, perineum, medial of the thigh, femoral region, pubic region, or dorsal of the penis. Transverse testicular ectopia, or cross testicular ectopia in other words, is a rare form of ectopic testis in which the ectopic testis is located in the contralateral scrotum [2]. TTE has first been defined by Lenhossek in 1886 during an autopsy and more than 100 cases have been reported in the English literature afterwards [4].

Several theories have been reported to explain the genesis of TTE. Berg proposed the possibility of the development of both testes from the same germinal ridge [5]. Kimura believed that if both vasa deferentia arose from one side, there had been unilateral origin but if there was bilateral origin, one testis had crossed over [6]. Gupta postulated that adherence and fusion of the developing Wolffian ducts took place early, and that descent of 1 testis caused the second one to follow [7]. Frey noted that defective ipsilateral gubernacular development might predispose to TTE. The mechanism by which the gubernaculum causes descent remains unclear, but scrotal enlargement secondary to gubernacular growth is one plausible explanation [8].

Often the right testis is found ectopic in patients with TTE and clinical signs include ipsilateral undescended testis and contralateral inguinal hernia. Cases might also present with incarcerated inguinal hernia that cannot be reducted $[2$, $4,9,10]$. The mean age at presentation is 4 years. In most cases, the correct diagnosis has not been made preoperatively, and the condition is revealed during herniotomy. Recently, ultrasound and magnetic resonance imaging have been suggested to determine preoperative localization of impalpable testes [11]. USG helps avoid the use of ionizing radiation and permits evaluation without sedation; however it might be difficult to perform in uncooperative or very young patients. Moreover, it is difficult to use USG to scan a testis cephalic to the internal inguinal ring [11]. The ectopic testis is identi- fied by the presence of characteristic bright signal on T2-W images and a linear low-signal structure which may represent the remnant of the gubernaculum testis on MRI [11].

TTE is classified in three clinical types according to the presence of additional abnormalities. Type I is the most common form where only inguinal hernia accompanies. Type 2 is associated with persistent or rudimentary Mullerian canal remnants. Type 3 is the rare form where more abnormalities (inguinal hernia, hypospadias, pseudohermaphrodite and scrotal abnormality) than Mullerian remnants are observed [12]. Isolated left undescended testis plus right transverse ectopic testis were determined in our case. This form is not included in any classifications. Vascular structures and ductus deferens of the testicles might be separated or united [2]. In our case, vascular structures and ductus deferens were separated. Ectopic testis should be treated surgically since it attaches to its site of location with fibrous structures. Treatment mainly consists of bringing the testis to its normal intrascrotal location surgically.

TTE is a rare genitourinary anomaly, the pathogenesis of which remains unclear. Both USG and MRI are the best diagnostic tools; US and MRI can provide more useful information compared to laparoscopy for preoperative diagnosis of TTE.

\section{Conflict of Interest}

The authors declare that they have no conflict of interest.

\section{References}

1. Fujita J. Transverse testicular ectopia. Urology. 1980;16(4):400-402.

2. Macedo A, Jr., Barroso U, Jr., Ottoni SL, Ortiz V. Transverse testicular ectopia and persistent Mullerian duct 
syndrome. J Pediatr Urol. 2009;5(3):234-236.

3. İnci $\mathrm{O}$, Kutlu K, Oruç N, Tamay G. Postmortem saptanan descensusunu tamamlamamış testisler ve beraber bulunan üriner sistem ve diğer malformasyonlar. Türk Üroloji Dergisi 1984;4:269-725.

4. Pandey A, Gupta DK, Gangopadhyay AN, Sharma SP. Misdiagnosed transverse testicular ectopia: a rare entity. Hernia. 2009;13(3):305-307.

5. Berg AA. VIII. Transverse Ectopy of the Testis. Ann Surg. 1904;40(2):223-224.

6. Kimura T. Transverse Ectopy of the Testis with Masculine Uterus. Ann Surg. 1918;68(4):420-425.

7. Gupta RL, Das P. Ectopia testis transversa. J Indian Med Assoc. 1960;35:547-549.

8. Frey HL, Rajfer J. Role of the gubernaculum and in- traabdominal pressure in the process of testicular descent. J Urol. 1984;131(3):574-579.

9. Ueno S, Yokoyama S, Hirakawa H. A case of transverse testicular ectopia with mullerian duct remnant. J Pediatr Surg. 2001;36(11):1710-1712.

10. Tatli D, Numanoglu KV. Transverse testicular ectopia associated with incarcerated inguinal hernia: a case report. Cases J. 2008;1(1):200.

11. Lam WW, Le SD, Chan KL, Chan FL, Tam PK. Transverse testicular ectopia detected by MR imaging and MR venography. Pediatr Radiol. 2002;32(2):126-129.

12. Ozturk H, Eroglu M, Uzunlar AK, Okur H. PERSISTENT Mullerian duct syndrome associated with transverse testicular ectopia: report of two cases. Fetal Pediatr Pathol. 2007;26(1):41-46. 